\title{
FOTO TERAPIJA I ART TERAPIJA: SLIKA KAO TERAPIJSKO SREDSTVO*
}

\begin{abstract}
Apstrakt: U radu se razmatra upotreba slike kao terapijskog sredstva promene ličnosti i njenog ponašanja. Pored toga u razmatranje je uključen i nov psihoterapijski pristup poznat kao integrativna art psihoterapija koji predstavlja originalnu kreaciju i doprinos psihoterapiji samog autora ovoga teksta. To je ujedno i kontekst za razmatranje zadate teme o slici kao terapijskom sredstvu u foto i art terapiji. Autor daje kratak opis ovog pristupa i ilustrativni primer iz svoje prakse.

Ključne reči: foto terapija, art terapija, integrativna art psihoterapija, slika kao terapijsko sredstvo, kreacija, integracija
\end{abstract}

\section{UVOD \\ ART TERAPIJA: OD NESVESNE SLIKE (SCENARIJA) DO SVESNOG ŽIVOTNOG PLANA}

Možemo već na početku ustvrditi da je slika kraljevski put u nesvesno, kao što je to Frojd u prošlom veku konstatovao za snove. Poznata je njegova tvrdnja da su snovi kraljevski put u nesvesno, a šta su snovi do zapravo većinom slike. I on sam konstatuje u svojoj čuvenoj knjizi „Uvod u psihoanalizu” da „treće dejstvo rada sna je psihološki najinteresantnije” i da se „ono sastoji u pretvaranju misli u vizuelne slike" (Frojd, 1969:162)

Postoje nesvesne slike ili slike koje potiču iz nesvesnog i slike koje su svesne i one predstavljaju naše svesne planove akcije ili naš svesni životni plan. Nasuprot njima, slike koje su nesvesne predstavljaju naš pretežno nesvesni životni plan (skript) ili tekući program, utemeljen na izvesnoj iracionalnoj odluci donetoj još u detinjstvu koju „,sugerišu, podržavaju i učvršćuju roditelji”, a „po kojem se vlada odrasla osoba u svim važnim trenucima svoga života, umesto po pravilima i zahtevima razuma" i svesno željenih odluka i htenja (Trebješanin, 2008: 446). Taj nesvestan životni plan se u transakcionoj teoriji naziva scenario ili skript (Berne, 1964;1972). To je razrađen plan koji predstavlja odgovor na pitanje: „Šta ćemo uraditi sa svojim životom?"

*nenam@eunet.rs 
Prema transakcionoj teoriji, postoje u načelu dva tipa životnog plana: 'gubitnički' i 'pobednički', i oba su uslovljena i određena prošlošću i nesvesnim odlukama i izborima, ali srećom, postoji i treća mogućnost, a to je život izvan 'scenarija' (skripta): svesno, slobodno i odgovorno izabran od strane pojedinca. Jedino tada možemo biti slobodna odgovorna i kreativna bića, a naš život naša kreacija, po vlastitom svesnom izboru.

\section{SLIKA KAO MEDIJATOR PROMENE}

Sliku možemo razumeti i kao medijator promene ili 'intervenišuću varijablu' u S-O-R shemi, gde ono 'O' ili odluka na osnovu slike (svesne ili nesvesne) 'interveniše' između situacije (S) i naših reakcija/akcija/ponašanja (R).

Kakve slike imamo u glavi (ili, kakve su nam misli koje stoje iza takvih slika), takav nam je i život i naša dela.

U NLP-u (neurolingvističko programiranje) lako se može uočiti mehanizam 'vidim-osećam' (see-feel), što znači da ono što vidimo/zamišljamo, to i doživljavamo, osećamo, pa u skladu sa tim se i ponašamo (Bandler \& Grinder,1979). Treba dodati, da slike nisu samo slike sećanja već i slike konstrukcije, tj., slike naše kreativne mašte. Pri tom isti mehanizam važi: to što u našoj glavi 'vidimo', tako se i osećamo i u skladu sa tim i ponašamo, delamo.

Na primer, ista fiziološka osnova (uzbuđenje) je i za strah i za ekstazu i egzaltaciju.

Samo ako imamo u glavi slike straha (npr. da nam postojeće erotsko uzbuđenje može nauditi, da možemo doživeti infarkt, završiti u bolnici, na operacionom stolu, čak i mrtvačnici-na groblju), možemo osetiti i dovesti sebe čak do panike, pa i smrti.

U davna vremena kada bi primitivni čovek 'greškom' pojeo totemsku životinju, zašta bi , po njegovom, pre svega, kolektivnom verovanju, trebalo da usledi kazna, obuzeo bi ga istog trenutka panični strah i on bi padao mrtav. „Prilikom prekršaja tabua primitivac se plaši kazne, najčešće teškog oboljenja ili smrti" konstatuje Frojd (Frojd, 1969:194) i prekoračenje učinjeno u neznanju ne smanjuje krivicu, jer kazna neumitno sledi prekršiocu. Tabu je, smatra Frojd, „zapovest savesti” i „njegovo kršenje dovodi do užasnog osećanja krivice”, koje je „,nepoznato po svom poreklu" (ibid, :191), ali može da ima fatalne, po osobu, posledice.

Da se podsetimo, još u grčkom mitu sagrešenje Edipovo nije oprošteno zbog toga što je učinjeno bez, čak i protiv njegovog znanja i volje (ibid, str. 191). Usledila je kazna.

U drugom slučaju, ako imamo u glavi ekstatičke slike (slike ljubavnog mističkog jedinstva u činu vođenja ljubavi), doživećemo ushićenje, ekstazu i egzaltaciju. Slike na hramovima iz Kadžuraha (Indija) predstavljaju najlepšu poemu ljudskom činu vođenja ljubavi. Nažalost, u poznatoj knjizi Kama Sutra, one su izvađene iz konteksta i postale su 'seksualni bukvar' ljubavnih poza prilikom vođenja ljubavi. 


\section{ODNOS SLIKA I NAŠIH MISLI, OSEĆANJA I PONAŠANJA}

Šta, dakle, dalje možemo zaključiti o odnosu slika i naših misli, osećanja i ponašanja?

Kao prvo, slika može poticati iz našeg nesvesnog, uslovljenih obrazaca mišljenja, osećanja i ponašanja, a što se u transakcionoj teoriji naziva scenario ili nesvestan životni plan (Berne, 1964; 1972).

Kada slika potiče iz nesvesnog i naša ponašanja su tzv. 'skriptna ponašanja'.

Kao drugo, izazov u psihoterapiji predstavlja da najpre, identifikujemo nesvesne slike i otkrijemo njihovo značenje, da bismo mogli da ih promenimo i re-konstruišemo/re-kreiramo u svesne slike koje reprezentuju to što mi stvarno želimo i hoćemo u životu, a što, ustvari, predstavlja i naš napravljeni/dogovoreni i zadati terapijski cilj (terapijski ugovor).

To znači da u ovom slučaju slika postaje terapijsko sredstvo promene: od nesvesne, najpre nepoznate, pa zatim prepoznate slike, ka svesnoj, željenoj slici terapijskom cilju, našoj novoj odluci o sebi i svom životu, umesto 'odigravanja' prošlosti u terminima sadašnjosti ili 'repetitia compulsia' o čemu je govorio Frojd uočivši kod svojih pacijenata ponavljanja koja su povratak večno istog, a što potiče iz prošlosti i nesvesnog

Geštaltisti bi to nazvali 'nezavršenim poslovima' iz prošlosti (Perls, 1969; Perls, Hefferline, Goodman, 1972).

Kao treće, dolazimo do nove svesne odluke, koja se preko slike jasno pokazuje. Slika potkrepljuje i utvrđuje promenu, kao ostvareni terapijski cilj i nov životni plan osobe koja je odlučila da bude svoj sopstveni kreator, a njen život od tada postaje rad na kreativnom ostvarivanju sopstvenog dela - svesnog životnog plana stvaraoca.

Svi mi možemo biti ili postati stvaraoci-kreatori sopstvenog života.

To je i nova pretpostavka koju potvrđuju brojna istraživanja savremene nauke (neuronauke, kvantne fizike, molekularne biologije, medicinske fiziologije, hemije i drugih (Talbot, 2006; Janik, 2008). Ali, isto tako, to je i stara istina sadržana u brojnim drevnim tekstovima svetih spisa, mudraca, kao i velikih i poznatih naučnika.

Ali, najpre, valja da upoznamo sebe, da bismo mogli zavoleti sebe. Kako, inače, i možemo voleti nekog ili nešto što ne poznajemo, što prethodno nismo videli i upoznali. Tako, zavoleti sebe znači, najpre, upoznati sebe i prihvatiti sebe kao celovito biće, izlečiti sve one podeljenosti, otuđenosti koje su nastale zastojima u razvoju i od nas stvorile fragmentirana bića, kako to Perls, po mom mišljenju, ispravno smatra (prema Bergeru, 1986). Biti svestan sebe - to istovremeno znači biti mentalno zdrav, u kontaktu sa svojim organizmičkim potrebama i relevantnim sredinskim mogućnostima za njihovo zadovoljenje. (Milenković, 1997). Prema Latneru, poznatom geštalt terapeutu (1974), konačni aspekt zdravog funkcionisanja i cilj terapije jeste svesnost. Po njemu, čovek je zdrav dotle dok je u kontaktu sa samim sobom i svojom okolinom, i obratno. Ozdravljenje je stvar obnavljanja svesnosti, a time i boljeg upoznavanja sebe. 
Prema Džonu Enrajtu (1973), mentalno zdrav čovek je onaj kod koga se svesnost može razviti bez blokiranja, dok neurotik ima blokiranu unutrašnju i spoljašnju svesnost. Neurotik pokazuje tendenciju da izbegne „kontinuum svesnosti”, ciljajući da zadrži koncept sebe kao deteta i na taj način reflektujući strah ili nevoljnost da preuzme odgovornost za sopstveni život „ovde i sada”.

Po mom mišljenju, čitav naš razvoj znači uvećanje i širenje svesnosti - sopstvenih vidika, svesti, njenih granica, prema spolja i prema unutra, u dubinu naše unutrašnjosti. (Milenković, 2002).

Sva dosadašnja otkrića psihologije, posebno psihoterapije, sledela su delfijski savet: „Upoznaj samoga sebe”. Neophodnost ove istine, potekle od grčkih filozofa (Sokrata) postoji trajno u čoveku - tragaocu za istinom u svim kulturama i religijama sveta. Za upoznavanje sebe čovek mora steći hrabrost - dublju, veću i plemenitiju od one koja je hrabrost ratnika - da siđe u nepoznate dubine sopstvene duše, svog bića. Stekavši jednom ovakvu hrabrost, (jer hrabrost je potrebna u prepoznavanju i suočenju sa onim delovima sebe koji su u senci, nepriznati i neprepoznati, često i neprihvatljivi od značajnih drugih, docnije neprihvaćeni i od nas samih) čovek, taj večni tragalac za smislom, polazi u večnu, nikad završenu avanturu čoveka-tragaoca, prema arhetipskom obrascu koji je, po Jungu, prisutan u dubinama psihe svakog pojedinca. Zatim na red dolaze naši bližnji, da i njih zavolimo, a to je tek moguće kada iskoračimo i nadrastemo naše vlastite egoističke interese i zakoračimo u sferu nadličnog, bezinteresnog, gde su drugi cilj, a ne sredstva, jer smo i mi prethodno postavili važan cilj sebi, a to je da budemo hrabri da realizujemo vlastite mogućnosti, da ostvarimo realnost za kojom stvarno čeznemo (Kolakovski, 1987.).

Da to ukratko rezimiramo:

O............. $>\mathbf{A}$

O - nove svesne životne odluke, namesto onih scenarijskih (skriptnih)

A - novo ponašanje, akcija, a ne re-akcija. $R$ je uvek znak da 'odigravamo' prošlost, a ne delamo na osnovu sadašnjosti - 'sada i ovde' na osnovu slobodne i odgovorne volje i odluke, a što je predstavljeno oznakom A.

Nadalje u životu, nakon uspešno završene psihoterapije, nove svesne životne odluke (O) kojima se ubuduće rukovodimo u našem novom ponašanju, praćene su našim akcijama (A) koje preduzimamo, a ne re-akcijama.

Kao ilustraciju navešćemo jednu simpatičnu zen priču o duhovnom učitelju koga su učenici na kraju njegovog života pitali kako je uspeo da proživi tako srećno svoj život. Njegov odgovor bio je vrlo kratak. „Vrlo jednostavno”, odgovorio je on. „Svakoga jutra zapitao bih sebe da li želim da tog dana budem srećen ili ne i odgovor je uvek bio isti. Tako sam uspeo srećno da proživim svoj život", završio je učitelj.

Zvuči vrlo izazovno, čak i neverovatno, ali i moguće za sve one koji idu 'putem kojim se ređe ide' da realizuju svoje mogućnosti u vidu svojih želja, ideala, 
vizija života kakvog žele, koji je 'po njihovoj meri', a kakav svako zaslužuje, bio on toga svestan ili ne.

U prilog tome govore i savermena naučna istraživanja usmerena na proučavanje 'Budinog mozga' i njegovog načina funkcionisanja.

Zašto baš Buda? možemo se zapitati.

U potrazi smo za boljim, srećnijim, mirnijim životom, a veliki učitelji-mudraci prošlosti mogu nas tome poučiti. Od njih možemo, ako smo spremni, nešto i naučiti..

Treba živeti ono što je univerzalno, kaže Heraklit, ono što čoveka čini istinskim, a to je ono što je u njemu istovetno sa svakim (Milenković, 2002: 71).

A šta je to što je istovetno svim ljudima?

Dalaj Lama je to lepo uočio i iskazao rečima, izrekavši jednu univerzalnu istinu: to što je zajedničko svim ljudima, bez obzira na rasu, poreklo, religijsku pripadnost, sociokulturne, ekonomske i društvene prilike i razlike, je da su svi ljudi isti po tome što žele da budu srećni i niko ne želi da pati (Dalai Lama \& Cutler, 1999).

Srećni ljudi su, pokazala su to brojna istraživanja, društveniji, fleksibilniji, kreativniji i tolerantniji, a što je još važnije, više skloni da vole i praštaju, za razliku od onih koji to nisu, koji su nesrećni, a koji su usredsređeni samo na sebe, skloni ruminaciji, socijalno povučeni, čak i antagonistički nastrojeni (Dalai Lama \& Cutler, 1999: 6).

Pa upravo, kako smo konstatovali, naš život i naša budućnost je u našim rukama i mi nismo sami, niti izolovani, već međusobno povezani. Naša odgovornost nije samo privatna stvar pojedinca, već smo mi odgovorni za čitav živi i neživi svet, čitavu našu planetu. Jer, mi smo svet, kako kaže Krišnamurti (Krishnamurti, 1972).

I upravo zbog toga i najnovija istraživanja (Hanson, 2011) potvrđuju da se iz 'doline plača' života može izaći na 'sunčanu stranu' života negujući i podržavajući pozitivne misli i dela i razusloviti se od prošlosti koja nas u najvećoj meri drži u škripcu i uči 'kako da upropastimo vlastiti život'.

\section{SAVREMENA NEUROPSIHOLOŠKA ISTRAŽIVANJA KOJA GOVORE U PRILOG POZITIVNE PSIHOLOGIJE - DA JE MOGUĆE DA BUDEMO STVARAOCI SOPSTVENOG ŽIVOTA I SREĆE, OPŠTEG BLAGOSTANJA}

Osnovna postavka savremene nauke mogla bi se sažeti ukratko u ključnu konstataciju, a to je da u zavisnosti od toga kako mi koristimo naš mozak, to menja naš mozak - na bolje ili na gore (Hanson, R., 2011, str.3). Ne možemo zaustaviti naš mozak da se ne menja. Jedino je pitanje: da li hoćemo pozitivne promene kakve mi to želimo.

Intersantna uputstva možemo pronaći sve više u knjigama koje se bave preporukama za bolji i zdraviji život, a koje su proistekle iz naučnih istraživanja, posebno neuronauke (Hanson, 2009; Hanson, 2011). 
Možemo, dakle, promeniti način na koji naš mozak radi kroz iskustvo i svakodnevnu praksu, a to je sve moguće zahvaljujući neuroplastičnosti našeg mozga. (Hanson, R. 2009; 2011).

Autor bestselera „Budin mozak” koji je već doživeo prevod i izdanja na 20 jezika Rik Henson, poznati neuropsiholog i osnivač Instituta za neuronauku na Kalifornijskom univerzitetu u Berkliju, čest gost i predavač na Oksfordu, Stanfordu i Harvardu, sažeo je rezultate savremenih neuropsiholoških istraživanja u nekoliko osnovnih zaključaka i postavki.

Ukratko, savremena istraživanja su pokazala da svakodnevna 'mala' praksa može promeniti način na koji naš mozak 'radi'. Naš možak se može 'istrenirati' praksama koje možemo upražnjavati svakodnevno da se zaštititimo od stresa, da poboljšamo naše raspoloženje i osnažimo se emocionalno (pronađemo naše vlastite snage - 'rezilijence').

Možemo ostvariti vlastito blagostanje, bio bi zaključak potekao iz serije ovih istraživanja.

Neke od postavki su:

1. Mi možemo menjati naš mozak zahvaljujući iskustvu na kome počiva i od koga zavisi naša neuroplastika. Naša neuroplastika, dakle, zavisi od našeg iskustva (Hanson, R. 2011: 1)

2. Jednostavne prakse-tj. jednostavne stvari koje možemo raditi rutinski svakodnevno, uglavnom unutar sebe, podržaće i povećati naš doživljaj sigurnosti i vrednosti, rezilijentnosti/otpornosti, efektivnosti, blagostanja, uvida i unutrašnjeg mira (Hanson, R. 2011: 1).

3. Postoji jedan-prema-jedan odnos između mentalnih i neuralnih aktivnosti.

To je kao dvosmerna ulica: kako se naš mozak menja, naš duh se menja; kako se naš duh menja, naš mozak se menja (Hason, R. 2011:2).

To znači, da to našta obraćamo pažnju, šta mislimo, osećamo i želimo i kako se ponašamo u životu, sve to 'skulpturira' naš mozak višestruko. Navešćemo neke od zaključaka:

a) Više 'zauzeti' regioni dobijaju više krvi, jer im je potreban više kiseonik i glukoza.

b) Neuralne veze koje su relativno neaktivne se povlače. Neka vrsta 'neuralnog Darvinizma': preživljavaju najzauzetiji: upotrebi ili izgubi.

c) Neuroni koji se 'pale' zajedno, 'rade' zajedno. Psiholog Donald Heb govori o aktivnim sinapsama, vezama između neurona - da oni postaju senzitivniji plus nastaju nove sinapse, koje proizvode deblje neuralne spojeve. Npr. ljudi koji upražnjavaju mindfulness meditaciju/molitvu razvijaju deblje slojeve neurona u insuli - regionu koji je aktiviran kada smo u skladu sa telom i našim osećanjima - i u delovima prefrontalnog korteksa (u prednjem mozgu) koji kontroliše našu pažnju (Hanson, R. 2011:2-3).

Ključna stvar je jednostavna: NAČIN KAKO KORISTIMO NAŠ MOZAK MENJA NAŠ MOZAK! 
Tradicionalno govoreći naš duh zauzima oblik na koji se oslanja. Npr. ako se obično okupiramo brigama, samokritikama i ljutnjom, tada će naš duh postepeno poprimiti oblik-razviće neuralne strukture i dinamiku-anksioznosti, smanjene vrednosti o sebi i reaktivnosti u odnosima sa drugima. S druge strane. ako redovno usmeravamo naš duh na to da uočavamo da smo u redu sada, da vidimo dobro u nama, da 'otpuštamo' posebno neprijatna iskustva, tada će naš mozak postepeno izgraditi oblik tihe snage, samopouzdanja i unutrašnjeg mira.

Zaključak je da MI NE MOŽEMO ZAUSTAVITI NAŠ MOZAK DA SE NE MENJA. Pitanje je samo: DA LI HOĆEMO DA TA PROMENA BUDE ONAKVA KAKVU ŽELIMO?

Na nama je da odlučimo. To je ključno mesto u samoj psihoterapiji: odluka da sledimo sebe i svoje unutrašnje potrebe i želje ili da živimo život koji uistinu i nije naš, već po diktatu i očekivanjima drugih.

Može nam ovo izgledati pojednostavljeno, ali valja uzeti u obzir psihoterapijsko iskustvo da to što nam se čini jednostavnim, to je i najteže ostvariti. Jednostavnost dolazi na kraju. Naučeni smo da između odluke i njene realizacije umećemo sve ono što komplikuje njenu realizaciju u vidu sumnji, suvišnih preispitivanja, neverice, i sl. Sve navedeno predstavlja upravo to što u psihoterapiji učimo kako da ga se oslobodimo, kako bismo bili ne samo efikasniji u životu, već i srećniji i zadovoljniji.

Koncept mindfulness-a ili kontinuirane svesnosti, svesnosti od trenutka do trenutka upravo je povezan sa jednostavnošću i vezom koja postoji između naše odluke i akcije koja valja da bude istovremene sa odlukom. Literatura koja se odnosi na ovaj novi i veoma obećavajući koncept u psihologiji i psihoterapiji je vrlo je brojna i ubedljiva (Watts, 1982; Wilber, 2002; Kabat-Zinn, 1994; 2012; Thich Nhat Hanh, 1987; 2008; Siegal, 2010).

I upravo pomenuti koncept mindfulness-a podržava i u skladu je sa navedenim najnovijim otkrićima i preporukama savremene nauke (Hanson, R. 2011).

\section{FILOZOFSKE I PSIHOLOŠKE OSNOVE PRISTUPA}

Naša realnost je naša konstrukcija kažu konstruktivisti. Ne postoji jedna univerzalna realnost koja se objektivno može posmatrati. Nema neutralnog znanja, ni saznanja. Sve naše percepcije daju značenje i kontekst posmatranome. Vrednosti su uključene u opažanje, kao i naše mišljenje, stavove i sudove o sebi, drugima i svetu oko sebe (Milenković, 1997).

Postmoderna misao ukazuje da je realnost u potpunosti relativna i uslovljena našom percepcijom i vrednostima eksplicitnim ili implicitnim koje je boje.

Kada posmatramo umetnost ili život iz bilo koje od perspektiva, postajemo više svesni kako naše nesvesno doprinosi značenju i kako jezik - podjednako verbalni i neverbalni - postaje medijator značenja.

Važne komponente u tome kako mi kreiramo našu realnost su naši lični sklopovi perceptivnih filtera, lični simbolizmi i jedinstvene 'unutrašnje mape' ili okviri za logičko mišljenje. 
U tom smislu, postmodernizam možemo shvatiti da je potekao iz egzistencijalističke i fenomenološke teorije, svo troje daju teorijski okvir za razumevanje kako ljudi crpu značenje iz slika.

Da zaključimo, camera/foto aparat kao naše oči ne beleže samo. Oni, takođe, posreduju. Oni su medijatori. Kulturni, etnički, sociološki, polni i drugi tipovi filtera ne mogu biti uklonjeni od osobe koja vrši posmatranje ili interpretaciju i na taj način značenje izdvojeno iz fotografije ili slike je personalno i idiosinkratičko koje se dešava između osobe i slike (Weiser, 1999).

Tako mi možemo fotografiju smatrati konstrukcijom realnosti pre nego objektivnom zabeleškom. (Weiser, 1999: 2).

\section{FOTO TERAPIJA: FOTOGRAFIJA KAO TERAPIJSKO SREDSTVO}

Fotografije su zamrznuti trenuci u vremenu, slike sećanja, načini da ispričamo priče iz prošlosti. One su dokument ne samo gde smo mi bili (u prošlosti), već pokazuju put kojim smo se zaputili i kojim idemo, znajući mi to ili ne. Mi možemo 'razgovarati' sa njima često i slušati dobro o tajnama koje nam one mogu saopštiti i reći.

U ovom tekstu potrudićemo se da pokažemo kako profesionalci koji se bave mentalnim zdravljem mogu koristiti lične fotografije svojih klijenata kao sredstvo za terepautsku komunikaciju i njihovu promenu u terapijskom radu.

Mada podjednako art terapija i foto terapija koriste metodologiju slikovne projekcije, to izgleda, bar na prvi pogled, da one to čine na različite načine. Art terapija se oslanja na klijentov unutrašnji rad da bi slika mogla da nastane spontano iz nesvesnog klijenta kroz proces crtanja/slikanja. Fotografije, s druge strane, se prave sa mesta gde aktuelni fizički sadržaj postoji. Tako, na primer, fotografija kuće će koristiti kao svoj sadržaj neku fizičku reprezentaciju kuće. Dok je art terapija zavisna od eksternalizovanog unutrašnjeg objekta, foto terapija je zavisna od internalizovanih spoljašnjih objekata.

Izgleda kao da se one odnose na različite aspekte ličnog simbolizma. Čak izgledaju uzajamno isključive, dok su ustvari integralno međupovezane, recipročne jedna drugoj, čak i različite u proizvodu i procesu jer se koriste dve vrste različitih medija. I jedna i druga terapija rade na osnovu davanja vizuelne forme osećanjima i pravljenja vidljivog još vidljivijim - neka vrsta „otkrivanja nesvesnog” (Weiser, J., 1999:9).

Sve kreativne art terapije daju formu osećanjima koja inače mogu da se opiru prevođenju u svesno ili verbalno istraživanje. To je razlog da su sve neverbalne ekspresivne terapije terapije zasnovane na senzornom iskustvu najprikladniji i najprimereniji pristupi za rad sa primarno vizuelnim metaforičkim jezikom nesvesnog - posebno foto terapija ili art terapija - ili, čak i bolje - obe kombinovano. 


\section{INTEGRATIVNA ART PSIHOTERAPIJA}

Kako bismo najkraće mogli opisati integrativnu art psihoterapiju?

Integrativna art psihoterapija predstavlja kreativnu upotrebu umetničkih medija od strane pojedinca kao terapijskog sredstva, verbalne i neverbalne, simboličke komunikacije u prisustvu psihoterapeuta u zaštićenoj i podržavajućoj terapijskoj sredini. Naglasak je na samom procesu stvaranja/kreacije, mada se uzima u obzir i finalni proizvod, njegov sadržaj i značenje za osobu koja ga je napravila, radeći zajedno na materijalu većinom nesvesnom koji uključuje neverbalnu, ali i verbalnu komunikaciju i vodeći do realizacije pozitivnog ishoda, odnosno, željenog terapijskog cilja/ishoda.

Neophodni elementi ovog procesa jesu: (1) pojedinac (klijent/pacijent), (2) psihoterapeut, (3) aktivna procedura koja uključuje neverbalnu ekspresiju i (4) upotreba umetničkih medija (slikanje, crtanje, vajanje, muzika, pokret i igra, drama, priča, poezija, video, film, kao i kombinovane tehnike.

Proces rada u integrativnoj art psihoterapiji zasniva se na izražavanju i prepoznavanju čovekovih najosnovnijih misli i osećanja poteklih iz nesvesnog, izraženih slikama, pre nego rečima. Umetnost se, dakle, može koristiti kao tip simboličkog govora i izražavanja osećanja i doživljavanja kroz slike.

Klijentova imaginacija i njegove slike su suština procesa. Slika na taj način ima višestruku primenu:

(1) Slika se može koristiti kao dijagnostičko sredstvo, kao dijagnoza postojećeg stanja u kome se pojedinac nalazi. Kada nam klijent dolazi na terapiju, slika nam precizno pokazuje gde se on nalazi u tom trenutku, što je dobar pokazatelj ne samo 'početnog stanja', već i pravca u kome želimo da idemo, tj. terapijskog cilja.

(2) Slika se može koristiti i kao način uspostavljanja i održavanja psihoterapijskog odnosa sa klijentom, tj. kao komunikacijsko sredstvo, kao psihoterapijska komunikacija. To je neophodno od početka do kraja psihoterapijskog rada sa klijentom - do kraja psihoterapije.

(3) Slika se može koristiti i kao psihoterapijsko sredstvo za dekonstrukciju ili re-konstrukciju početne slike u željenu, a koja predstavlja pozitivni terapijski ishod i cilj terapijskog tretmana. Od 'scenarijske', nesvesne slike ka svesnoj, željenoj, a što predstavlja novi životni plan klijenta i realizaciju terapijskog cilja.

(4) Slika može predstavljati pozitivan terapijski ishod/cilj tretmana i prognozu za budućnost. Znači, slika može poslužiti i kao prognostičko sredstvo.

Slika omogućava premošćavanje jaza i finiju sintezu između verbalnog i neverbalnog, svesnog i nesvesnog, spoljašnjeg i unutrašnjeg, govorenja i činjenja, realnosti i fantazije, racionalnosti i intuicije. Sve to pomaže i omogućava jedinstvo tela, duše i duha.

Ovo je uistinu jedan holistički i integrativan pristup koji ne samo da proširuje našu svest o sebi, drugima i svetu, već dopire i do onih zapretih, duboko potisnutih emocija, a isto tako 'završavanjem nezavršenih poslova iz prošlosti', omogućava 
nam i pomaže da idemo u budućnost, da kreiramo život kakav želimo da živimo i budemo vlastiti stvaraoci sebe i svoje budućnosti.

\section{PRIMER IZ PRAKSE}

U nastavku teksta biće prikazane slike kao ilustracije terapijskog rada sa klijentkinjom S. uz korišćenje slika kao terapijskog sredstva, kako dijagnostičkoprognostičkog, komunikacijskog, tako i transformativnog, u proizvođenju željene promene - pozitivnog terapijskog ishoda.

Klijentkinja u trenutku dolaska na psihoterapiju, između ostalih problema koje ima uključujući i zdravstvene, se oseća neuspešnom u partnerskoj vezi koja je, kako i sama shvata, iluzorna i ne može da se realizuje u realnosti, jer partner koga ona voli ne želi vezu i beži čak i u bukvalnom smislu, geografski, s jednog kraja sveta na drugi pronalazeći razne uzbudljive, avanturističke poslove i izgovore za svoja 'bekstva'.

Biće prikazani njeni radovi, a to su njeni fotokolaži, slike i crteži koji prikazuju tok terapijskog rada sa njom kao i njena odluka i promena da od iluzorne realnosti koja je drži u škripcu sa 'neuhvatljivim' partnerom kreira realnost koju ona želi po svojoj želji i koja ujedno predstavlja željeni terapijski cilj: povezivanje odvojenih realnosti kroz shvatanje i prihvatanje svoje patnje i bola zbog 'izneverene' ljubavi, najpre prema ocu, a docnije i njegovim predstavnicima, zatim, napuštanje one iluzorne realnosti i kreaciju one željene u kojoj ima više mogućnosti da ostvari partnersku vezu. Ta nova realnost za koju se ona odlučila ujedno je predstavljala i kraj njenih neuspelnih veza, predstavljala je njenu odluku da pronađe partnera koji ne bi više bio „ponavljanje prošlosti” (koja je za nju bila nesrećna, posebno detinjstvo, razvod roditelja i život najpre sa jednim roditeljem (majkom), do puberteta, a zatim beg onom drugom (ocu) koji je živeo u inostranstvu i njeno veliko razočaranje u susretu sa njim koji nije bio u stanju da se stara o njoj, bolestan, bez posla i sredstava, koji je i sam živeo u svojim fanatzijama i deluzijama da će jednog dana postati pisac i s idejom da će se jednom on i njegova žena pomiriti, s kojom je vrlo kratko živeo pre nego što se razveo i otišao. Otac je u međuvremenu umro, a S. je bila prinuđena da se stara sama o sebi još od prvog dana njenog odlaska ocu u inostranstvo, grubo i šokantno suočena sa novom ralnošću bez zaštite, ljubavi i brige roditelja. Prinuđena je bila da se snalazi u novom svetu sa novim ,čak i surovim, pravilima igre.

S. je inače devojka tridesetih godina, umetnica, koja doživljava ,između ostalog, i neuspešne veze sa partnerima; najpre brak koji je bio beg od nepodnošljive realnosti suočenja sa ocem koji ju je izneverio svojim obećanjima i u njenim očekivanjima, beg partneru koga je volela, ali koji je i sam bio problematičan, koga naziva 'emocionalnim bogaljem', koji je dilovao drogu i bio ovisnik, od koga je otišla, da bi pronašla novog partnera i vezu sa čovekom koji i sam beži iz realnosti i neuhvatljiv je poput ptice. Ona ga je i zvala 'plava ptica' inspirisana pesmom Čarlsa Bukovskog koji upravo opisuje čoveka koji duboko u sebi krije 
svoje nežno, ranjivo, osećajno biče, ne pokazuje ga svetu, drži u kavezu svoju 'plavu pticu' o kojoj niko ne zna i nikad je nije i ne može videti i upoznati.

Najverovatnije je S. i odabrala baš takvog 'neuhvatljivog' partnera i sama bežeći od suočenja sa sobom, svojom povredom i boli.

Slika br. 1 upravo ilustruje iluzornu potragu klijentkinje za 'plavom pticom'. Pesma-metafora Čarlsa Bukovskog „Plava ptica” predstavlja i početak našeg psihoterapijskog rada, predstavljanje njene tadašnje pozicije ,između sna i realnosti” ili „,u iluzornoj potrazi za plavom pticom”.

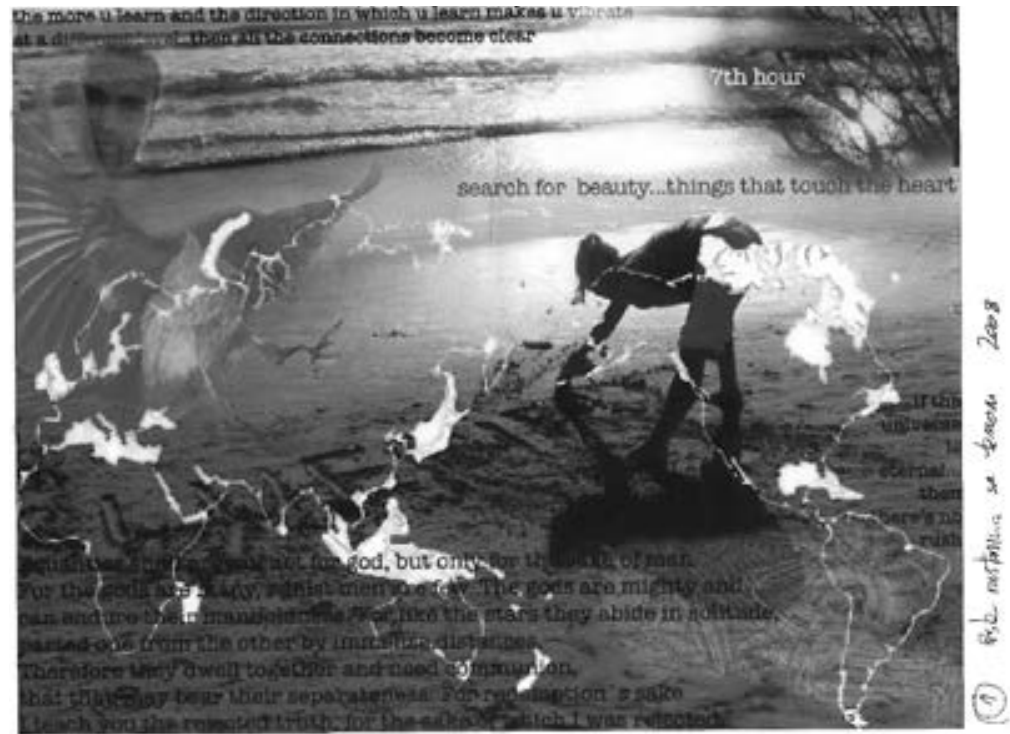

(Slika 1) Između sna i realnosti ili U potrazi za plavom pticom (fotokolaž)

Vidimo da je plava ptica smeštena u levi ugao papira koji se obično po pravilu odnosi na prošlost i događaje iz prošlosti. Plava ptica je biće prošlosti koje je u letu, ali se let ptice i njena figura devojčice ne nalaze $u$ istom planu, okrenute su u suprotnom pravcu. Ona je sebe predstavila u liku devojčice (ne 30-godišnje devojke) koja ispisuje na pesku svoje želje-očekivanja, nadanja: „u potrazi za lepotom-stvarima koje diraju srce". Tu je iscrtana i mapa kontinenata i svetova koji su nespojivi - svet odakle je krenula u potragu za „lepim, dobrim i istinitim” iz svoje zemlje, svog detinjstva (od svoje majke) u drugi svet, nepoznati, u kome se osećala nedobrodošlom, ćak i neprijateljski nastrojenim (ka svom ocu).

U nastavku terapijskog i introspektivnog putovanja na kome je došla do brojnih bolnih uvida koji je vode prekidanju iluzornih očekivanja pojavljuje se slika br. 2 (fotokolaž) koja datira iz vremena susreta sa njim, jednim kratkim letnjim susretom koji se odigrao u nekom morskom ambijentu.. 


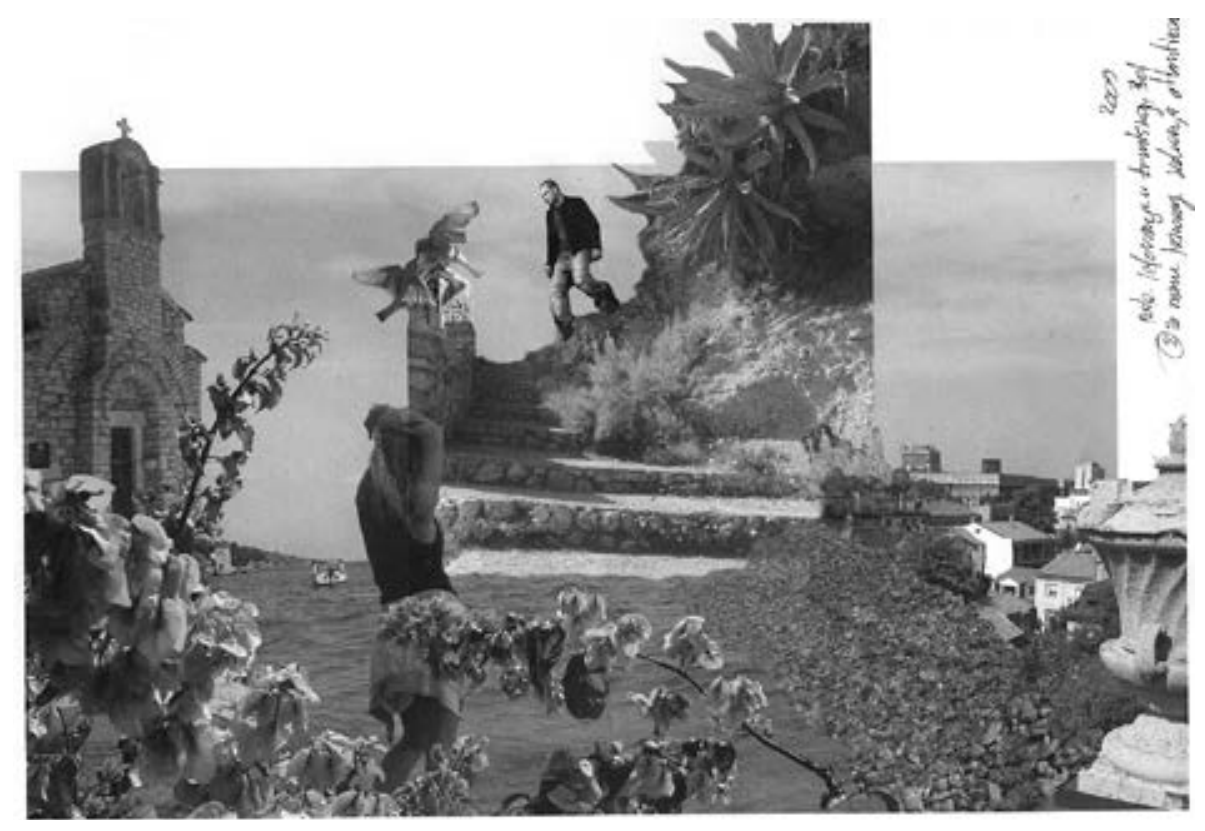

(Slika 2) U očekivanju (i susret) sa mitskim partnerom (fotokolaž)

Na ovom fotokolažu uočljivi su različiti, odvojeni svetovi/realnosti. On, njen mitski partner, dalek i neuhvatljiv (njena 'plava ptica') dolazi odozgo, iz gornjeg dela slike koji je obično rezervisan za maštu, sanjarenje i ideje koje neko ima o nekome ili nečemu. On kao da 'pada sa neba'. Pri tom je plan gornje polovine slike rezervisan za nebo (odakle se on pojavljuje) i donji - obale, gde ga ona čeka da se pojavi, razdvojeni velikom vodom (morem), koja razdvaja ove dve realnosti. Ona je sebe prikaazla na ovoj slici kao ne više devojčicu,već devojku. On se vidi jasnije, ali uz njega je i 'plava ptica' koja ga i simbolično predstavlja.

Tu su i primorske kuće, čak i crkva, bugenvilije, ali ni na ovoj slici njihov susret koji se zbio u realnosti je 'opterećen' prošlošću, i nemogućnošću realnog susreta i realizacije partnerskog odnosa kakav ona želi da ostvari.

Još uvek je prisutan nezavršen rad sa prošlošću, kao i iluzija kojom je ispunjavala svoj dotadašnji život.

Na slici br. 3 dolazi do pokušaja približavanja, ali koji je takođe osuđen na neuspeh.

Vidimo da su na istom drvetu, ali ne i na istoj grani. Oni u izvesnoj meri dele neki zajednički svet duhovnih vrednosti, ali ne i više od toga. Ispod nje, okačena na donju granu je njihova uramljena slika, što znači, da se u realnosti još nisu sreli, već samo u nekoj lepoj slici i priči koju bi zajedno želeli da dožive. Vidimo da je naslikan snežni pejsaž, a da su oni obućeni ne u skladu sa spoljašnjom realnošću koju nam slika dočarava. 


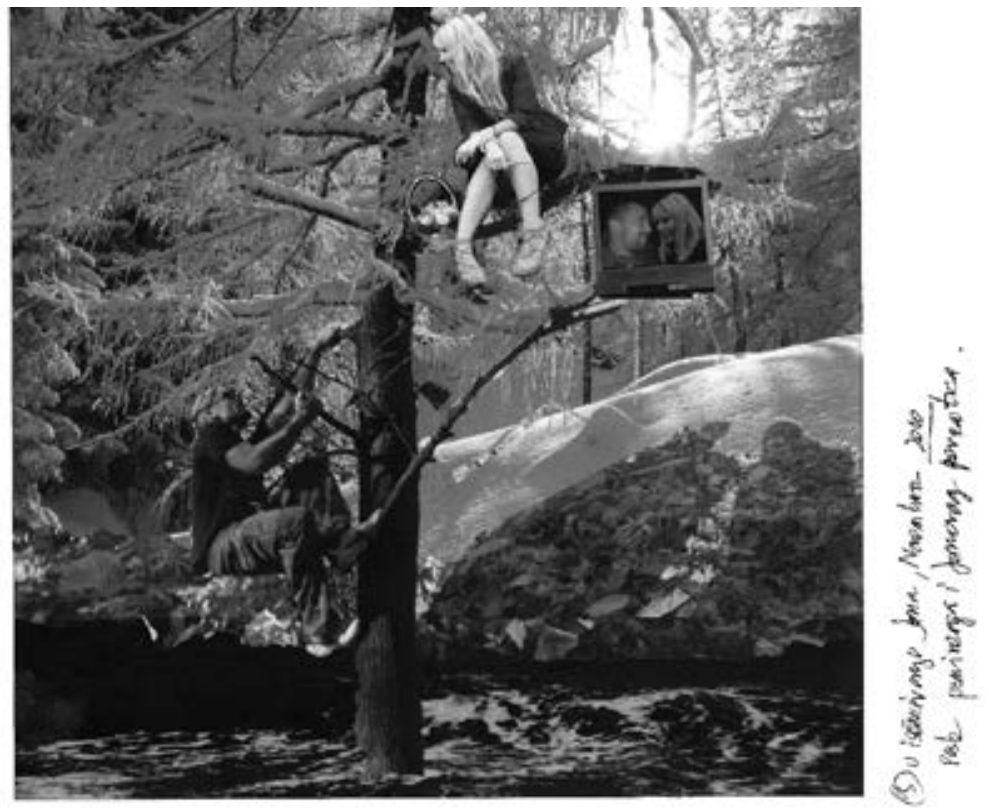

(Slika 3) Pokušaj približavanja - (fotokolaž)

Zatim sledi slika „Siluete” nacrtana masnim bojicama koja predstavlja izvestan pomak u terapijskom radu, jer su njih dvoje napokon zajedno - hodaju držeći se za ruke, ali su samo 'siluete', ne još stvarni likovi. Ovaj crtež nastao je nakon nekih terapijskih radova gde je S. odlučila da još jednom 'proveri' njihov odnos u realnosti i prekine vezu - raskine sa njim ukoliko dobije konačni odgovor njegove nespremnosti za zajednički život u realnosti.

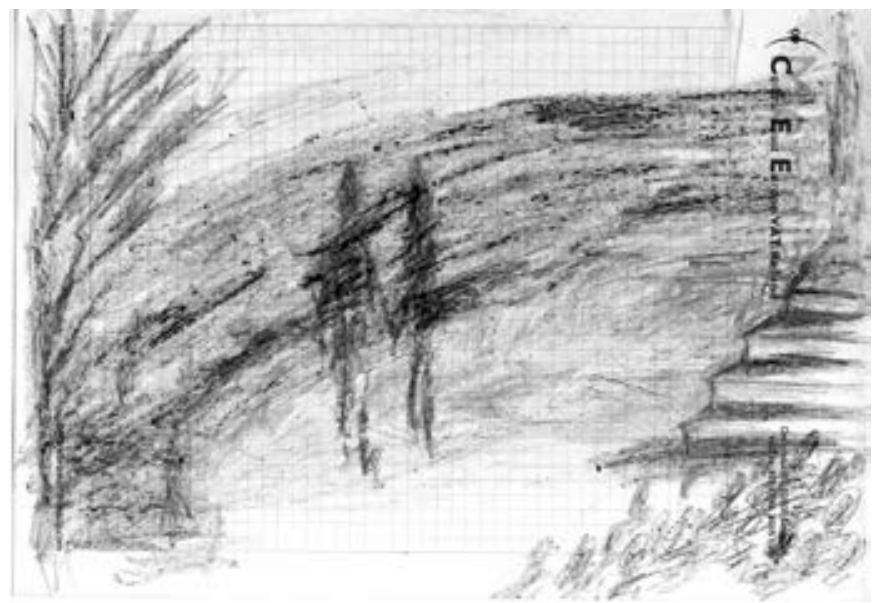

(Slika 4) Siluete (crtež masnim bojicama) 


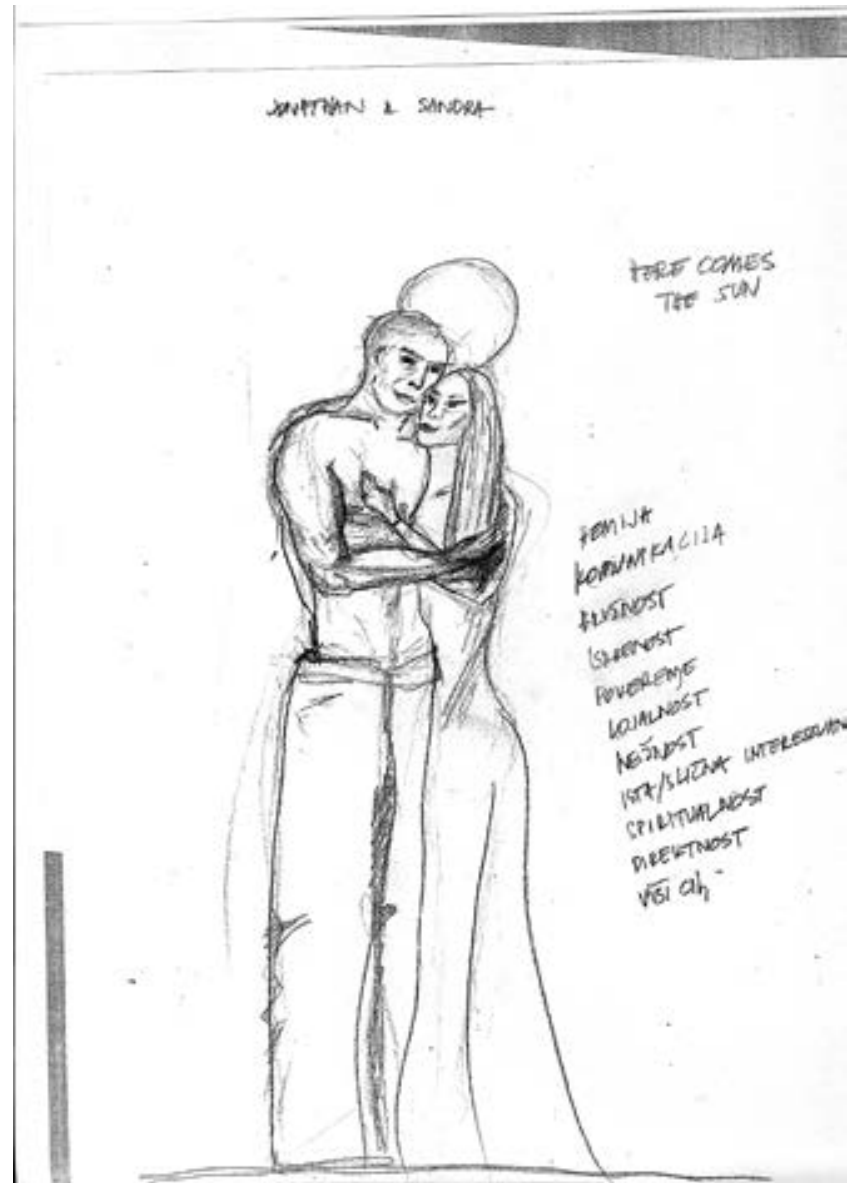

(Slika 5) Skica partnerskog odnosa kakav S. želi u realnosti, nazvan "Here comes the sun" (Evo, sunce se rađa)

Crtež br. 5 predstavlja i završetak rada klijenkinje i rastanak sa iluzijom i 'neuhvatljivim' partnerom izražen u pismu koje mu je S. uputila kada je odlučila da napusti svoju iluziju partnera koga je u njemu videla i prihvati realnost takvom kakva je, ali koja obećava nov početak i nove izazove, kao i nova učenja koja će joj otvoriti nove perspektive i pružiti nove mogućnosti realizacije sebe kao bića koje voli i koje je voljeno, ispunjenog mirom, ljubavlju i radošću življenja.

Crtež je nacrtan olovkom i sa desne strane su ispisane osobine koje ona želi da njen budući partner ima, kao što su: poverenje, iskrenost, lojalnost, nežnost, spiritualnost, itd.

S. mu je u pismu napisala sledeće: Pošto se nisu susreli u realnosti, ona je odlučila da mu saopšti svoju odluku o prekidu veze i svom odlasku, makar njihova veza nikada i nije bila situirana u realnosti. 
Rekla mu je da je bilo vrlo lako da on pobegne iz njene (odvojene) realnosti, jer je ona od njega napravila ideju koju je nazvala ,iluzija moje plave ptice” uz pomoć koje je ona i mogla da živi u iluziji i sa njom, a ne u realnosti. I „to bi moglo biti perfektno da nije bilo imaginarno". Ali, ona se „suočila sa realnošču onakvom kakva ona jeste” i videla da što su njeno „srce i duša želeli” bila je samo imaginacija, njena „odvojena realnost”. Na kraju je završila pismo upućeno njemu da „neće da spali mostove između njih, već samo da ubije iluziju svog emotivnog života”. Zahvalila mu se što ju je ,probudio mnogo puta i na mnogo nivoa” I rekla da će mu uvek biti zahvalna na tome”. Završila je pismo rečima „Univerzum je večan i uvek nam pruža istinu koja nam je potrebna. Mi samo treba da je vidimo".

Odgovor je usledio od njega: da je to vrlo pošteno i hrabro od nje i da ona ima dosta snage u sebi koju on ceni i poštuje da pronađe u životu to što je za nju najbolje, svoj pravi put.

\section{UMESTO ZAKLJUČKA}

Koristeći imaginaciju i sve druge oblasti umetnosti i umetničkog stvaranja u art psihoterapiji mi možemo stvoriti naše vlastito remek delo, a to smo mi sami. I, umesto da budemo žrtve naše ,skriptirane” sudbine, mi transcendiramo postojeću realnost, stvarajući novu po našoj meri koja odgovara našim mogućnostima.

Umetnost nas otvara za nove uvide, ona olakšava promenu od dogmatskog ka kritičkom i kreativnom mišljenju; ona ne podražava i ne adaptira se postojećoj realnosti (mimesis), već ona stvara novu realnost (poiesis).

Umetnost ima vrlo važnu kognitivnu funkciju: ona povećava ljudski kapacitet za fleksibilnost, slobodu i kreativnost. U psihoterapiji smo svedoci oslobođenja od mentalnih i telesnih blokada koje se dešavaju na kraju kao ishod uspešnog art psihoterapijskog tretmana.

Konačno, umetnost ima terapeutsku ulogu. Ona podržava snage u čoveku koje su fundamentalne u prevazilaženju najgorih životnih situacija i izazova. Ona predstavlja jednu od sedam rezilijenci o čemu govori bračni par Volin (Volin \& Volin, 1993), ali ona isto tako predstavlja i moćan način rada u terapijskoj praksi.

Bergson (1993) opisujući njenu primarnu funkciju kaže da nas umetnost dovodi licem u lice sa realnošću, a ja bih tu dodala, i sa samima sobom. U tom smislu umetnost je forma re-kreacije pojedinca, njegovog obnavljanja, transformacije i realizacije njegovih mogućnosti.

Tako je psihoterapija terapija naše duše, ali i duha. Stara izreka kaže da ono što radimo dolazi od onoga što prethodno mislimo. Pronađimo to što je unutar nas i pronaći ćemo kakva će nam budućnost biti. Jer, budućnost je već sada.

\section{LITERATURA}

Bandler, R. \& Grinder, J. (1979). Frogs into Princes. Moab, Utah: Real People Press Berger, J. (1986).Treći roditelj. Beograd: Nolit 
Bergson, A (1993). Smeh. Beograd: Lapis

Berne, E. (1964). Games People Play. New York: Grove Press

Berne, E. (1972). What Do You Say After You Say Hello? London: Corgi Books

Dalai Lama, \& Cutler, C. (1999). The Art of Happiness. London: Coronet Books

Enright, J. (1973). An Introduction to Gestalt techniques. U knjizi: Fagan \& Shepherd, I. (Eds). Life Techniques in Gestalt Therapy. New York: Harper \& Row

Frojd, S. (1969). Uvod u psihoanalizu. Beograd: Matica srpska

Frojd, S. (1969). O seksualnoj teoriji. Totem i tanu. Beograd: Matica srpska.

Hanson, R. (2011). Just One Thing. Oakland: New Harbinger Publication

Janik, P. (2008). Kvantna medicina. Beograd: Esotheria

Kabat-Zinn, J. (1994). Wherever You Go, There You Are. New York: Hyperion

Kabat-Zinn, J. (2012). Mindfulness for Beginners: Reclaming the Present Moment - and Your Life. Boulder: Sounds True, Inc.

Kolakovski, L. (1987). Religija. Beograd: BIGZ

Krishnamurti,G.(1972). You are the world. NY: Harper \& Row

Latner, J. (1974).The Gestalt Therapy Book. New York: A Bantam Book

Milenković, S. (2002). Psihoterapija i duhovnost. Beograd: Čigoja

Perls, F. (1969). Gestalt Therapy Verbatim. Lafayette, Cal: Real People Press

Perls,F., Hefferline, R., Goodman, P. Gestalt Therapy. New York: A Delta Book

Siegal, R. (2010). The Mindfulness Solution: Everyday Practices for Everyday Problems. New York: The Guilford Press

Talbot, M. (2006). Holografski univerzum. Subotica: Artist

Thich Nhat Hanh (1987). The Miracle of Mindfulness. Boston: Beacon Press

Thich Nhat Hanh (2008). Mindful Movements. Berkeley: Parallax Press

Trebješanin, Ž. (2008). Rečnik psihologije. Beograd: Stubovi kulture

Volin \& Volin (1993). Rezilijentna ličnost. Beograd: Prosveta/Nispred

Watts, A. (1982). Put zena. Beograd: NIRO „Književne novine”

Weiser, J. (1999). Photo Therapy Techniques. Vancouver: Photo Therapy Centre

Wilber, K. (2002). Bez granica. Beograd: Babun

Snežana Milenković

\section{FOTO TERAPIJA I ART TERAPIJA: SLIKA KAO TERAPIJSKO SREDSTVO}

\section{REZIME}

U radu se razmatra upotreba slike kao terapijskog sredstva promene ličnosti i ponašanja klijenata. Fokusira se na art i foto terapiju, kao i na integrativnu art psihoterapiju kao novi integrativni, holistički pristup koji je originalna kreacija i doprinos psihoterapiji samog autora ovog teksta. Autor daje kratak opis ovog pristupa i ilustrativni primer iz svoje prakse. Fotografije su zamrznuti trenuci u vremenu, ogledalo sećanja, najbolji način da se ispriča priča iz prošlosti. Ova prezentacija će pokazati kako profesionalci mentalnog zdravlja mogu koristiti klijentove lične fotografije kao sredstva za terapijsku komunikaciju i promenu. Mada i art i foto terapija koriste metodologiju slikovne projekcije, može se učiniti prvobitno da one to čine na različite načine. Art terapija se oslanja na klijentove unutrašnje preokupacije koje potiču iz nesvesnog spontano izražene kroz 
proces crtanja ili slikanja. Fotografije, s druge strane, će biti snimljene na mestima gde fizički sadržaj aktualno postoji. Fotografija kuće će koristiti kao sadržaj neki fizički prikaz kuće. Dok art terapija zavisi od eksternalizovanih unutrašnjih objekata, izgleda kao da se bavi različitim aspektima ličnog simbolizma. Mada foto terapija i art terapija izgledaju uzajamno isključive, one su integralno povezane među sobom, recipročne su, mada različite u krajnjem produktu i procesu zato što se koriste dva različita medija. Obe rade na osnovu pridavanja vizuelne forme osećanjima i čineći vidljivo još vidljivijim - neka vrsta ,otkrivanja nesvesnog'. Poslednje pomenuta, integrativna art psihoterapija, koristi sliku na isti način kao i prethodno pomenute ekspresivne terapije, ali na kompleksniji način, holistički i integrativan, koji kombinuje i druge načine psihoterapijskog rada u radu sa klijentima, kao što su: psihodinamski, psihodramski, telesnoterapijski, sistemski, geštaltistički, transakcionoanalitički i transpersonalni. Ona radi na više nivoa: intrapersonalno, interpersonalno i transpersonalno s ciljem da integriše telo, dušu i duh. Takođe, ona pruža mogućnost ujedinjenja obe hemisfere i sinteze različitih vrsta doživljavanja i izražavanja.

Ključne reči: foto terapija, art terapija, slika kao terapijsko sredstvo, kreacija, integracija

Snežana Milenković

\section{FOTO TERAPIJA I ART TERAPIJA: SLIKA KAO TERAPIJSKO SREDSTVO}

\section{SUMMARY}

This paper discusses the use of images as psychotherapeutic tools to induce change of personality and behavior of the clients. It focuses on Art and Photo therapy as well as Integrative art psychotherapy, a new integrative holistic approach to psychotherapy, which is an original creation and contribution made by the author of this text. The author briefly explains the mentioned approach and presents an illustrative example from her practice. Photographs are frozen moments in time, the mirror of memory, the best way to retell the stories from the past. This presentation will show how mental health professionals can use clients' personal photos as tools for therapeutic communication and change. Although both Art and Photo therapy utilize the methodology of pictoral projection, it may seem initially that they do so in very different ways. Art therapy relies on a client's internal concerns to emerge from the unconscious through the process of drawing or painting spontaneously produced by the client. Photographs, on the other hand, will be taken at the place where the physical content actually exists. A photograph of a house will use as content some physical representation of a house. Since Art therapy is dependent on externalized internal subjects, it appears as though they deal with different aspects of personal symbolism. Although Photo therapy and Art therapy seem mutually exclusive, they are integrally interrelated, reciprocal to each other, even though different in product and process because two different kinds of media are used. They both work on the basis of giving visual form to feelings and making the visible more visible - a kind of , unconsciousness raising'. The last mentioned - Integrative art psychotherapy - utilizes the image the same way as the previously mentioned expressive therapies but in a more complex way, holistic and integrative, combining some other psychotherapeutic ways of working with clients as psychodynamic, psychodramatic, body therapy work, systemic, gestalt, transactional analytic, and transpersonal. It works on multiple levels: intrapersonally, interpersonally, and transpersonally, aiming to integrate the body, soul and mind. It gives a possibility to unify and make syntesis of both hemispheres and different kinds of experiences and expressions.

Key words: Art and Photo therapy, Integrative art psychotherapy, image as terapeutic tools, creation, integration. 